\title{
ANÁliSE ECONÔMICA DA PRODUÇÃO DE ACEROLA PARA MESA, EM JALES-SP: UM ESTUDO DE CASO ${ }^{1}$
}

\author{
RICARDO ALESSANDRO PETINARI² \& MARIA APARECIDA ANSELMO TARSITANO ${ }^{3}$
}

\begin{abstract}
RESUMO - Este trabalho foi realizado no município de Jales, localizado na região noroeste do Estado de São Paulo, com o objetivo de analisar economicamente o cultivo da acerola para mesa. Para se estimar a matriz de coeficientes técnicos, os custos de implantação e produção e os indicadores de lucratividade da cultura, os dados foram levantados junto a um produtor e técnicos da região, em 2000. Os custos de implantação e formação da cultura nos dois primeiros anos atingiram $\mathrm{R} \$ 2.462,09 / \mathrm{ha}$, e a receita líquida estimada para a acerola a partir do $5^{\circ}$ ano foi de $\mathrm{R} \$ 9.061,55$, correspondendo a um índice de lucratividade de $59,23 \%$, resultado bastante atraente, principalmente para produtores interessados em diversificarem suas atividades voltadas especificamente para a fruticultura.
\end{abstract}

Termos para indexação: acerola, custo de produção, indicadores de lucratividade

\section{ECONOMIC ANALYSIS OF THE PRODUCION OF WEST INDIAN CHERRY FOR TABLE IN JALES-SP: A STUDY OF CASE}

\begin{abstract}
This work was carried out in Jales town, located in northwest region of São Paulo State, having the aim to analyze economically the west Indian cherry crop. For estimate the technical coefficients, the planting costs, production and the indicators of the profitable of the culture, the data were acquired from one producer and technicians of the region, in year of 2000. The costs of planting and formation in two years of the culture had reached $\mathrm{R} \$ 2.462,09 / \mathrm{ha}$ and the liquid prescription estimate for west Indian cherry on the fifth year was $\mathrm{R} \$ 9.061,55$ corresponding to an index of profitable of $59.23 \%$, sufficiently attractive result, mainly for the producers interested in diversifying their activities specifically for fruits crops.
\end{abstract}

Index terms: Malpighia glabra, production cost, profitable indicators

\section{INTRODUÇÃO}

A acerola (Malpighia glabra L.) é uma planta rústica e resistente, propaga-se com facilidade em toda a parte do mundo. $\mathrm{O}$ interesse pela acerola e os estudos sobre suas potencialidades econômicas, no entanto, só foram despertadas a partir dos anos 40, quando se descobriram, na porção comestível da fruta, altos teores de ácido ascórbico, ou seja, vitamina C (Araújo, 1994).

Dados preliminares, referentes a 1996, indicam que a produção brasileira foi de 32.990 toneladas, representando uma área de 11.050 hectares com acerola. A principal região brasileira produtora de acerola é a Nordeste, com 22.964 toneladas, em uma área de 7.237 ha, seguida da região Sudeste, com 5.063 toneladas, em uma área de 1.550 ha. A produção da região Nordeste representa cerca de $70 \%$ da produção brasileira, e a da região Sudeste 15\% (Instituto Brasileiro de Geografia e Estatística, 2000).

Dentre os principais Estados brasileiros produtores de acerola, Pernambuco representa $23,11 \%$ da produção nacional, seguido pelos Estados do Ceará, com 14,32\%, e São Paulo, com $11,40 \%$. Na região Sudeste, o Estado de São Paulo é que tem maior participação: 74,26\%, seguida pelo Estado de Minas Gerais, com 19,32\% (Instituto Brasileiro de Geografia e Estatística, 2000).
Segundo Venâncio (2000), além da geléia, a acerola pode ser consumida de várias outras formas: "in natura" ou em suco, licor, xarope, sorvete, em calda e pastas. Pode ainda ser usada na preservação de outros sucos frigorificados ou no enlatamento industrial, porque a vitamina $\mathrm{C}$ é um antioxidante natural. Da acerola, pode ser feito também um excelente vinho e, nos Estados Unidos, a acerola também é encontrada na forma de comprimidos vendidos em farmácias; cada comprimido contém $100 \mathrm{mg}$ de vitamina $\mathrm{C}$.

Na região Oeste do Estado de São Paulo, a cultura de acerola encontra-se bastante difundida, tanto no município de Jales, onde alguns agricultores já se encontram com a cultura em produção, porém em áreas menores, como no município de Junqueirópolis-SP, cuja finalidade principal da produção é a indústria. Nesta região, alguns produtores se uniram e fundaram uma associação de produtores de acerola, com o objetivo de obter um melhor preço na venda e também para a compra de equipamentos para processamento da acerola, para fabricação de geléia, doces, etc.

A região Oeste do Estado de São Paulo vem destacando-se na produção de frutas, e, segundo o Programa Setorial Integrado de Promoção de Exportações de Sucos Tropicais, elaborado pela Associação das Indústrias Processadoras de frutos

1 (Trabalho 139/2001). Recebido: 10/09/2001. Aceito para publicação: 04/06/2002.

2 Engo ${ }^{\text {Agr }}{ }^{-}$Mestrando em Agronomia FE / UNESP - Ilha Solteira - SP, Bolsista FAPESP, E-mail: petinari@ agr.feis.unesp.br. Rua oito, $n^{\circ}$ 2875, centro, CEP15.700-000, Jales-SP.

3 Prof $^{\mathrm{a}}$ Dr $^{\mathrm{a}}$ do Departamento de Fitotecnia, Tecnologia de Alimentos e Sócio-Economia da FE/UNESP, Av. Brasil Centro $n^{\circ}$ 56, Caixa Postal 31, CEP15.385-000, Ilha Solteira-SP. E-mail: maat@agr.feis.unesp.br. 
Tropicais, esta região é apontada como um dos principais pólos de frutas tropicais no Brasil (Ruggiero, 2001).

Muito embora seja considerada uma cultura rentável, é fundamental a realização de pesquisas mostrando não apenas resultados referentes à parte técnica (manejo da cultura), mas também de análise econômica.

Desta forma, o trabalho teve como objetivo estimar e analisar economicamente a produção de acerola para mesa em Jales-SP, determinando a matriz de coeficientes técnicos, os custos de implantação e produção, e os indicadores de lucratividade.

\section{MATERIAL E MÉTODOS}

\section{Levantamento de dados}

O levantamento dos dados necessários à realização do trabalho nos aspectos ligados à tecnologia, produção e preços foi efetuado através de um produtor rural do município de Jales, que utiliza técnicas de produção difundidas na região e apresenta produtividade e ótima qualidade da fruta.

Os dados foram obtidos durante o ano de 2000, mediante entrevistas e acompanhamento realizado diretamente ao produtor rural e técnicos da Casa da Agricultura e de empresas ligadas à área, utilizando-se de planilhas, com a finalidade de levantar e aprender as questões mais ligadas à tecnologia de produção e identificar locais e formas de comercialização da acerola.

Assim como em Miqueletto et al. (2000), em função de se aplicar especificamente a uma propriedade, os resultados do trabalho devem ser considerados com a devida atenção, pois, em qualquer atividade econômica, pode-se ter produtividades variando de acordo com o sistema de cultivo e com o gerenciamento adotado.

\section{Estrutura do custo de produção e avaliação econômica}

O custo de produção foi baseado na estrutura do custo operacional total (COT) de produção e do custo total de produção (CTP) utilizada pelo Instituto de Economia Agrícola (IEA), proposta por Matsunaga et al. (1976). O custo operacional total compõe-se dos seguintes itens: operações mecanizadas e implementos, operações manuais, materiais, outras despesas, juros de custeio $(5,75 \%$ a.a.), depreciação do equipamento de irrigação e do pomar. Já o custo total de produção é composto pelo custo operacional total, outros custos fixos e a remuneração da terra. Nas operações que refletem o sistema de cultivo, foram computados os materiais consumidos e o tempo necessário de máquinas e mão-de-obra para a realização de cada operação, definindo, nestes dois casos, os coeficientes técnicos em termos de hora/máquina e homem/dia. O custo da mão-de-obra foi composto basicamente pela diária paga pelos produtores aos trabalhadores envolvidos no processo. A depreciação dos bens considerados fixos, ou seja, os que prestam serviços por mais de um ciclo produtivo, foi calculada utilizando-se do método linear. Para a remuneração da terra, foi considerado o valor médio do arrendamento na região. Os preços foram coletados no mês de novembro de 2000 e expressos em Real (R\$) e Dólar (US\$), sendo 1 dólar $=\mathrm{R} \$ 1,94$.

Nos custos convencionais de produção para culturas perenes, como as culturas requerem vários anos, elaboram-se planilhas individuais para cada ano de implantação, formação e produção, assim como, neste trabalho, considerou-se vida útil de 10 anos para acerola. Tais custos são elaborados através de cortes seccionais no tempo (cross-section), em que o capital fixo, como máquinas e equipamentos, entram na forma de fluxo (depreciação) e não na forma de estoque (aquisição de bens de capital) (Neves e Shirota, 1989).

Para se analisar a lucratividade da cultura da acerola, estimou-se a receita bruta como o produto da produção, pelo preço de venda; o lucro operacional, pela diferença entre a renda bruta e o custo operacional total e o índice de lucratividade igual à proporção da receita bruta que se constitui em recursos disponíveis (Martin, 1997).

\section{RESULTADOS E DISCUSSÃO}

A Planilha do custo operacional total de implantação e manutenção encontra-se detalhada na Tabela 1.

O custo operacional total de implantação no primeiro ano foi de $\mathrm{R} \$ 1.937,48$ (US\$998.70) por ha, destacando-se as despesas com mudas R $\$ 0,70 /$ muda (US\$0.36) e tutores, que representam 32\% deste total; este valor é mais que o dobro do apresentado por Nehmi et al. (2001), que foi de US\$0.15 cada. Em seguida, aparecem as despesas com fertilizantes (17\%), compostos por esterco se curral, fórmulas 04-30-10 e 20-05-20, calcário, cloreto de potássio e micronutriente FTE. Neste primeiro ano, deve-se ressaltar, dos tratos culturais, as despesas com irrigação: R \$29,86 (US\$15.39), que é uma operação fundamental, não somente para a boa formação das mudas, mas também para a obtenção de frutos de boa qualidade (padronizados) e melhor distribuídos durante o ano.

No segundo ano, as despesas com a formação atingem $\mathrm{R} \$ 524,61$ (US\$270.42), representando cerca de um quarto das despesas obtidas no primeiro ano. Deste total, $38 \%$ refere-se às despesas com fertilizantes (esterco de curral e calcário), 29\% com tratos culturais manuais (desbaste dos brotos, adubação de cobertura, controle de plantas daninhas e coroamento) e $23 \%$ com tratos culturais mecanizados (irrigação e controle de plantas daninhas).As despesas com implantação e formação da cultura da acerola, nos dois primeiros anos, somaram $\mathrm{R} \$ 2.462,09 / \mathrm{ha}$ (US\$1,269.12).

No terceiro ano, o custo total de produção foi $\mathrm{R} \$ 4.688,52 /$ ha (US\$2,416.76), sendo que desse total, cerca de $40 \%$ representam despesas com operações manuais, que são compostas por tratos culturais (desbaste dos brotos, adubação de cobertura, controle de plantas daninhas e coroamento) e colheita (colheita, embalagem, preparo das caixas de papelão e perfuração dos sacos plásticos). Podemos notar que as despesas com colheita são responsáveis pelo alto custo de produção. A seguir, as despesas com embalagens representam quase $20 \%$ do custo total. $\mathrm{Na}$ colheita, quando as frutas são comercializadas in natura, estas são colocadas diretamente em sacos plásticos com capacidade para $500 \mathrm{~g}$, sendo os mesmos perfurados para possibilitar uma maior conservação da fruta e, após, embaladas em caixas de papelão, com capacidade média para $5 \mathrm{~kg}$.

No quarto ano, o custo total de produção foi de $\mathrm{R} \$ 5.859,53$ (US $\$ 2,101,14$ ) e da mesma forma as operações manuais, por causa da colheita, apresentam maior participação (42\%)

Rev. Bras. Frutic., Jaboticabal - SP, v. 24, n. 2, p. 411-415, agosto 2002 
no custo total, seguidas pelas despesas com embalagens (22\%).

A partir do quinto ano, a produção estabiliza-se e o custo total de produção atinge R $\$ 6.238,45 /$ ha (US\$3,215.70), sendo que as operações manuais representam $45 \%$ do custo total de produção. Do total das despesas com operações manuais (R $\$ 2.791,47$, ou seja, US\$1,438.90), 96\% são despesas com a colheita, o mesmo acontecendo com as despesas com material (R\$1.493,74) (US\$769.97), em que as despesas com embalagens representam $97 \%$ deste total.

Se considerarmos apenas as despesas com operações e material, o custo foi de $\mathrm{R} \$ 4.420,00$ (US $\$ 2,266.66)$, valor este inferior ao obtido por Nehmi et al. (2001), que publicaram pela primeira vez o custo de produção da acerola para região Noroeste do Estado de São Paulo (US\$3,300.00/ha), isto considerando também somente as despesas com operações e material.

Podemos verificar que as diferenças maiores se referem às despesas com embalagens e com a depreciação do equipamento de irrigação, que foram consideradas separadas no nosso trabalho.

Deve-se ressaltar que a consorciação da acerola, nos 3 primeiros anos com culturas de ciclo curto, além de manter a área livre de plantas daninhas, pode diminuir as despesas com implantação da cultura.

\section{Indicadores de lucratividade}

Para calcular os indicadores de lucratividade da acerola, foi estimado um valor médio recebido pelo produtor para a caixa de 5,0 kg, de $\mathrm{R} \$ 9,00$ (US\$4.64) ou R $\$ 1,80 / \mathrm{kg}$, e considerado que toda a produção é vendida para "mesa". As frutas são colocadas em sacos plásticos e embaladas em caixas de papelão, para serem comercializadas através de um intermediário, nos boxes da Companhia de Entrepostos e Armazéns Gerais de São Paulo.

A produção citada em Nehmi et al. (2001), 33,28 t/ha, a partir do quinto ano, é bem superior à obtida pelo produtor, que é de 8,5 t/ha. Essa baixa produção é devida à perda ainda no campo, uma vez que o mesmo só comercializa acerola para mesa; quando a colheita se destina à indústria, o rendimento é muito maior, porém o preço obtido com a venda do produto é bem inferior.

Os indicadores de lucratividade para a cultura da acerola

TABELA 1 - Custo operacional e custo total de implantação, formação e produção de 1 ha da cultura da acerola para mesa em Jales $\mathrm{SP}$ (666plantas/ha, com espaçamento de 3 X $5 \mathrm{~m}$ ) em R $\$$, novembro/00.

\begin{tabular}{|c|c|c|c|c|c|c|}
\hline \multirow[b]{2}{*}{ DESCRIÇÃO } & \multirow[b]{2}{*}{ ESPECIFICAÇÃ O } & \multicolumn{3}{|c|}{ Implantação e Formação } & \multicolumn{2}{|c|}{ Produção } \\
\hline & & $\begin{array}{l}\text { Ano } 1 \\
\text { Valor } \\
\end{array}$ & $\begin{array}{l}\text { Ano } 2 \\
\text { Valor } \\
\end{array}$ & $\begin{array}{l}\text { Ano } 3 \\
\text { Valor } \\
\end{array}$ & $\begin{array}{l}\text { Ano } 4 \\
\text { Valor } \\
\end{array}$ & $\begin{array}{c}\text { Ano } 5 \text { ao } 10 \\
\text { Valor }\end{array}$ \\
\hline \multicolumn{7}{|l|}{ A. OPERAÇÕES MECANIZADAS } \\
\hline a1. Preparo do solo & $5,65 \mathrm{HM}$ & 86,05 & & & & \\
\hline a2. Implantação & $15,70 \mathrm{HM}$ & 223,60 & & & & \\
\hline a3. Tratos culturais & $28 \mathrm{HM}$ & 90,00 & 90,00 & 91,10 & 90,00 & 90,00 \\
\hline a4. Irrigação & $1.640,64 \mathrm{kw} / \mathrm{h}$ & 29,86 & 29,86 & 29,86 & 44,79 & 44,79 \\
\hline Subtotal A & & 429,51 & 119,86 & 120,96 & 134,79 & 134,79 \\
\hline \multicolumn{7}{|l|}{ B - OPERAÇÕES MANUAIS } \\
\hline b1. Implantação & $13,52 \mathrm{HD}$ & 162,24 & & & & \\
\hline b2. Tratos Culturais & $63,13 \mathrm{HD}$ & 195,90 & 152,40 & 176,40 & 116,40 & 116,40 \\
\hline b3. Colheita & $559,40 \mathrm{HD}$ & & & 1683,72 & 2354,06 & 2675,07 \\
\hline Subtotal B & & 358,14 & 152,40 & 1860,12 & 2470,46 & 2791,47 \\
\hline \multicolumn{7}{|l|}{ C. MATERIAL } \\
\hline c1. Fertilizantes & $13.962,32 \mathrm{~kg}$ & 333,52 & 201,44 & 214,10 & 214,10 & 41,60 \\
\hline c2. Defensivos & 0,10 Litro & 1,65 & & & & \\
\hline c3. Mudas & 800 Unidades & 626,60 & & & & \\
\hline c4. Embalagens & 21.330 Unidades & & & 913,99 & 1277,88 & 1452,14 \\
\hline Subtotal C & & 961,77 & 201,44 & 1128,09 & 1491,98 & 1493,74 \\
\hline Custo operacional efetivo (C.O.E.) & & 1749,42 & 473,70 & 3109,17 & 4097,23 & 4420,00 \\
\hline Outras despesas $(5 \%)$ & & 87,47 & 23,68 & 155,46 & 204,86 & 221,00 \\
\hline Juros de custeio & & 100,59 & 27,23 & 173,64 & 235,59 & 254,15 \\
\hline Depreciação equip. irrigação & & & & 487,50 & 487,50 & 487,50 \\
\hline Depreciação do pomar & & & & 307,76 & 307,76 & 307,76 \\
\hline Custo operacional total (C.O.T.) & & $1.937,48$ & 524,61 & 4233,53 & 5332,94 & 5690,41 \\
\hline Custo por kg & & & & $\mathbf{0 , 7 9}$ & 0,71 & 0,67 \\
\hline Remuneração da terra & & & & 206,61 & 206,61 & 206,61 \\
\hline Outros custos fixos & & & & 248,38 & 319,98 & 341,42 \\
\hline Custo total de produção & & & & 4688,52 & 5859,53 & 6238,45 \\
\hline Custo total por $\mathrm{kg}$ & & & & $\mathbf{0 , 8 8}$ & $\mathbf{0 , 7 8}$ & $\mathbf{0 , 7 3}$ \\
\hline
\end{tabular}


encontram-se discriminados na Tabela 2.

Os dois primeiros anos não foram considerados devido não se ter produção significativa. Em virtude da maior produtividade obtida do terceiro $(5.350 \mathrm{~kg} / \mathrm{ha})$ para o quinto ano $(8.500 \mathrm{~kg} /$ ha), a receita bruta aumentou quase $60 \%$, passando de $\mathrm{R} \$ 9.630,00$ para $\mathrm{R} \$ 15.300,00$, os custos de produção aumentaram $36 \%$ e a receita líquida cresceu quase $70 \%$.

A receita líquida obtida no terceiro ano, de $\mathrm{R} \$ 5.035,28$, foi suficiente para pagar as despesas com implantação e formação da cultura nos dois primeiros anos, R $\$ 2.462,09 /$ ha (US\$1,269.12). Neste caso, como o investimento com o equipamento de irrigação foi de R $\$ 3.900,00 /$ ha (US\$2.010,31), somente com a receita líquida do quarto ano é que o produtor vai recuperar este valor inicial.

A partir do quinto ano, a produção estabiliza-se, assim como os custos totais de produção, cuja a receita líquida foi de $\mathrm{R} \$ 9.061,55$ (US $\$ 4,670.90$ ), o índice de lucratividade (receita líquida/receita bruta) de 59,23\% e o preço mínimo que se deve obter pela venda da fruta para cobrir todos os custos (menos a remuneração do produtor) foi de $\mathrm{R} \$ 0,73 / \mathrm{kg}$, mostrando, com isso, o grande retorno que a produção de acerola para mesa proporciona ao produtor da região.

Estes resultados podem ser melhor visualizados na Figura 1.

Os resultados evidenciam que a produção de acerola é lucrativa e pode ser mais uma opção do produtor rural interessado em diversificar sua produção.

\section{CONCLUSÕES}

1. A análise econômica da produção de acerola para mesa permitiu, por um lado, estimar os custos de implantação e produção e, por outro lado, evidenciar a potencialidade da acerola na região de Jales. Alguns produtores estão produzindo diretamente para o mercado e não para indústria, o que, em alguns locais, tem gerado muitos problemas e descontentamentos de produtores, principalmente na época de maior produção.

2. Há potencial para o crescimento da produção e comercialização da acerola nesta região, especialmente para os produtores que procurarem adequar-se às exigências de qualidade, além da possibilidade de um grupo de produtores se unirem, para reduzirem os investimentos iniciais, e agregarem valor, através do processamento da fruta.

3. Estes resultados indicam ainda a necessidade de realização de mais estudos técnicos e econômicos, com ênfase à pós-colheita, embalagens e acondicionamento. A falta de alternativas de comercialização do produto também é um ponto importante a ser melhorado, pois boa parte da safra é perdida, em função de, em certas épocas do ano, o preço não ser satisfatório.

\section{AGRADECIMENTO}

Ao Sr. Antônio Moreira Teixeira, pela colaboração na realização deste trabalho.

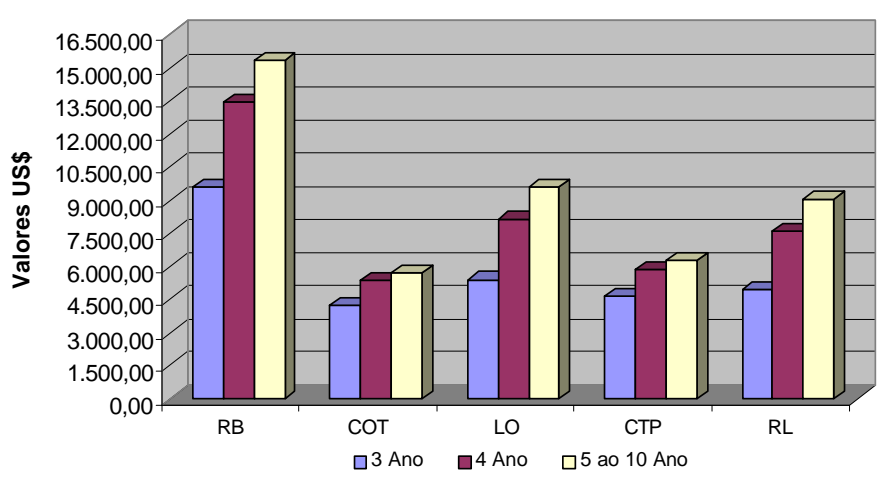

Figura 1 - Receita bruta, custo operacional total, lucro operacional, custo total de produção e a receita líquida da cultura da acerola para mesa, em Jales-SP, novembro de 2000 .

Tabela 2 - Indicadores de lucratividade da cultura da acerola para mesa, município de Jales - SP, novembro / 00.

\begin{tabular}{|c|c|c|c|}
\hline Itens & $3^{\circ}$ Ano & $4^{\circ}$ Ano & $5^{\circ}$ ao $10^{\circ}$ Ano \\
\hline Valor unitário ${ }^{1}$ & $1,80 \mathrm{R} \$ / \mathrm{kg} \quad(0.93 \mathrm{US} \$ / \mathrm{kg})$ & $1,80 \mathrm{R} \$ / \mathrm{kg} \quad(0.93 \mathrm{US} \$ / \mathrm{kg})$ & $1,80 \mathrm{R} \$ / \mathrm{kg} \quad(0.93 \mathrm{US} \$ / \mathrm{kg})$ \\
\hline Produtividade (kg/ha) & 5350 & 7480 & 8500 \\
\hline Receita bruta & $\mathrm{R} \$ 9.630,00 \quad(\mathrm{US} \$ 4,963.92)$ & $\mathrm{R} \$ 13.464,00 \quad(\mathrm{US} \$ 6,940.21)$ & $\mathrm{R} \$ 15.300,00 \quad(\mathrm{US} \$ 7,886.60)$ \\
\hline $\mathrm{COT}$ & $\mathrm{R} \$ 4.139,72$ (US\$2,133.88) & $\mathrm{R} \$ 5.332,94$ (US\$2,748.94) & $\mathrm{R} \$ 5.690,41 \quad(\mathrm{US} \$ 2,933.20)$ \\
\hline Lucro operacional & $\mathrm{R} \$ 5.490,28 \quad(\mathrm{US} \$ 2,830.04)$ & $\mathrm{R} \$ 8.131,06$ (US\$ 4,191.27) & $\mathrm{R} \$ 9.609,59 \quad(\mathrm{US} \$ 4,953.40)$ \\
\hline Índice de lucratividade & 57,01 & 60,39 & 62,81 \\
\hline Preço de equilíbrio & $\mathrm{R} \$ 0,77$ (US\$0.40) & $\mathrm{R} \$ 0,71 \quad(\mathrm{US} \$ 0.37)$ & $\mathrm{R} \$ 0,67$ (US\$ 0.35$)$ \\
\hline Custo total de produção & $\mathrm{R} \$ 4.594,72$ (US\$2,368.41) & $\mathrm{R} \$ 5.859,53(\mathrm{US} \$ 3,020.38)$ & $\mathrm{R} \$ 6.238,45 \quad(\mathrm{US} \$ 3,215.70)$ \\
\hline Receita líquida & $\mathrm{R} \$ 5.035,28$ (US\$2,595.51) & $\mathrm{R} \$ 7.604,47$ (US\$ 3,919.83) & $\mathrm{R} \$ 9.061,55(\mathrm{US} \$ 4,670.90)$ \\
\hline Índice de lucratividade (\%) & 52,29 & 56,48 & 59,23 \\
\hline Preço de equilíbrio & $\mathrm{R} \$ 0,86$ (US\$ 0.44) & $\mathrm{R} \$ 0,78$ (US\$0.40) & $\mathrm{R} \$ 0,73$ (US\$ 0.38$)$ \\
\hline
\end{tabular}

Fonte: Dados básicos da pesquisa

1 dólar $=\mathrm{R} \$ 1,94($ novembro/2000) 


\section{REFERÊNCIAS BIBLIOGRÁFICAS}

ARAÚJO, P.S.R. Acerola. Campinas: Fundação Cargill. 1994. 81p. INSTITUTO BRASILEIRO DE GEOGRAFIA EESTATÍSTICA.

Senso Agropecuário 1996. Disponível: <http://www.ibge.gov.br/ ibge/estatística/economia/agropecuário/censoagro/35/ d35_t10.shtm>. Acesso em:20 nov 2000.

MARTIN, N. B. et al. Sistema “CUSTAGRI": sistema integrado de custos agropecuários. São Paulo: IEA/SAA, 1997. 75p.

MATSUNAGA, M. et al. Metodologia de custo utilizada pelo IEA. Agricultura em São Paulo. São Paulo, v.23, n.1, p.123-39, 1976.

MIQUELETTO, D.F.; CARDOSO, J.L.; MARTIN, N.B. Avaliação econômica da produção comercial de uva niagara: uma aplicação do software CUSTAGRI 1.0. Informações Econômicas, São Pau- lo, v.30, n.11, p. 7-15, 2000.

NEHMI, I.M.D.; FERRAZ, J.V.; NEHMI FILHO, A.; SILVA, M.L. da. (Coord.) AGRIANUAL 2002: anuário da agricultura brasileira. São Paulo: FNP Consultoria \& Comércio, 2001. p.136-7.

NEVES, E.M., SHIROTA, R. Consideração sobre a importância, determinação e avaliação de custos. Piracicaba-SP: FEALQ/DESR/ ESALQ/USP, 1989.14p. (mimeo).

RUGGIERO, C. (Editor). Programa setorial integrado de promoção de exportações de sucos tropicais. Informativo Sociedade Brasileira de Fruticultura, Jaboticabal, v.20, n.2, p.4-5, jun. 2001.

VENÂNCIO, M. Produtor faz pesquisas e experiências com acerola. Disponível em: <http://www.jornal.atarde.com.br/arq01/ ru160105.html>. Acesso em: 08 out 2000. 